\title{
Response of forest distribution to past climate change: An insight into future predictions
}

\author{
LIU HongYan* \& YIN Yi \\ College of Urban and Environmental Sciences and MOE Laboratory for Earth Surface Processes, Peking University, Beijing 100871, China
}

Received March 15, 2013; accepted July 3, 2013; published online August 8, 2013

\begin{abstract}
Vegetation dynamics could lead to changes in the global carbon and hydrology cycle, as well as feedbacks to climate change. This paper reviews the response of forest dynamics to climate change. Based on palaeoecological studies, we summarized the features and modes of vegetation response to climate change and categorized the impacts of climate change on vegetation dynamics as three types: climate stress on vegetation, buffer effects by non-climatic factors, and perturbation of the vegetation distribution by stochastic events. Due to the openness of the vegetation system and the integrated effects of both climatic and non-climatic factors, the vegetation-climate relationship deviates far from its equilibrium. The vegetation distribution shows a non-linear response to climate change, which also makes it difficult to quantify the modern vegetation distribution in terms of specific climatic factors. Past analog, space-for-time-substitution and Dynamic Global Vegetation Models (DGVMs) are three approaches to predicting the future vegetation distribution, but they have all been established on the assumption of vegetation-climate equilibrium. We propose that improving DGVMs is a future task for studies of vegetation dynamics because these are process-based models incorporating both disturbance (e.g. fire) and the variability in Plant Functional Types (PFTs). However, palaeoecological results should be used to test the models, and issues like spatial and temporal scale, complexity of climate change, effects of non-climatic factors, vegetation-climate feedback, and human regulation on vegetation dynamics are suggested as topics for future studies.
\end{abstract}

biogeography, Quaternary ecology, climate change, pollen, Dynamic Global Vegetation Models (DGVMs)

Citation: Liu H Y, Yin Y. Response of forest distribution to past climate change: An insight into future predictions. Chin Sci Bull, 2013, 58: 4426-4436, doi: $10.1007 / \mathrm{s} 11434-013-6032-7$

Forest and steppe are two predominant vegetation types, with forest occupying about one third of the land surface. Changes in the distribution of vegetation have strongly affected not only the earth's carbon balance [1,2] and water cycle [3], but also the feedback between vegetation and climate change [4]. Will global warming lead to the expansion or decline of forests in the future? Will measures taken to address climate change concerns, such as the forestation of grasslands, successfully expand the distribution of the forest or have the reverse effect? These scientific and practical questions have been the focus of extensive discussion in the scientific community [5]. In China, for example, as an adaptation to climate change, the area covered by forest will increase from the current $20 \%$ to $23 \%$ in 2020 . Due to the lack of physical space in the wet climate zone, much planting is

*Corresponding author (email: 1hy@urban.pku.edu.cn) taking place in the current forest-steppe ecotone [6]. Will the future climate benefit forests in the current forest-steppe ecotone? To answer this question we need to make accurate predictions of future climate forcings of vegetation dynamics.

Vegetation dynamics in the past and present are critical to predictions of vegetation response to climate change in the future [7]. Through a review of previous work, we have attempted to summarize the general principles and modes of vegetation response to climate change, and to explore how to accurately predict climate-induced changes in vegetation under the future climate change scenarios.

\section{Spatiotemporal scales of vegetation dynamics and the corresponding research methods}

Research into vegetation dynamics is an essential part of 
biogeography, an interdisciplinary field of study that has developed over the course of more than a century, from the conventional "study of the geographical distribution of plants, animals and other organisms" [8] to "the study at all possible scales of analysis of the distribution of life across space, and how, through time, it has changed" [9].

At different spatial and temporal scales, vegetation dynamics are determined by different driving forcings, and the internal response modes of vegetation systems are also different. At seasonal time scales, wind, erosion, landslides, flooding, earthquake and drought events can change the species composition and structure in a plant community, thereby influencing internal process within the plant community, such as productivity, plant diseases and pest attacks. Fire generally occurs with an annual to decadal frequency, and contributes to vegetation dynamics by altering interspecific competition and initiating forest gap dynamics. Human-induced secondary succession processes in the plant community occur at a centennial scale, whereas climateinduced species migration occurs at a millennial scale. On a time scale of ten thousand years, the evolution of ecosystems is triggered by glacial-interglacial cycles (Figure 1(a), (b)).

Research into vegetation dynamics is therefore carried out using different methods to investigate phenomena at different temporal and spatial scales. Studies into dynamic vegetation processes occurring over short time scales (1-10 years) are mainly based on long-term observation and control experiments $[12,13]$ and on remote sensing data such as aerial photos and satellite images [14]. Processes occurring over medium time scales (100-1000 years) are mainly investigated using evidence from tree rings and historical literature [15]. Research into processes over longer time scales (1000-10000 years) mainly relies on evidence from plant macrofossils and pollen [1] (Figure 1(c)).

Both the dominant forcing and the vegetation response span a range of spatial and temporal scales. At large spatial and temporal scales, the dynamics of vegetation distribution represent a significant biogeographical process, and this article therefore focuses on patterns and processes at large scales.

\section{Response of forest distribution to past climate change}

\subsection{Modes of vegetation response to past climate change}

Sediment pollen assemblages have often been used in previous studies to reconstruct the paleoclimate by means of transfer functions between surface pollen and climate. It is hard to avoid a circular argument when investigating the response of vegetation to past climate change because both the vegetation and the climate are inferred from the same pollen database [16]. In recent years, an increasing number of high resolution palaeoclimatic datasets have been developed from proxies other than pollen, such as oxygen isotopes from ice cores and stalagmites, thereby modifying the global and regional temperature curve [17]. The emergence of these independent datasets is helpful for the accurate modeling of vegetation response to past climate change.

Quaternary Ecology (also called Quaternary Paleoecology), which has developed from the conventional field of Palynology, investigates the mechanisms of vegetation response to past climate change $[10,16]$. In recent years, the following findings have been made in terms of the response of paleovegetation to paleoclimate change.

(1) High latitude mountains become a refuge for plants during glacial periods. Mountains in the low latitudes were suggested to act as a refuge for plants during the ice ages. Previous studies have commonly argued that forest in high latitudes in the northern hemisphere has spread gradually from a refuge in the low latitudes during the postglacial period. The implied species migration rate reached dozens to even hundreds of meters per year $[18,19]$. This rate, however, was suggested to be unachievable by recent studies [20]. An alternative to this high migration rate is the preservation of forest refuges in northern Europe and
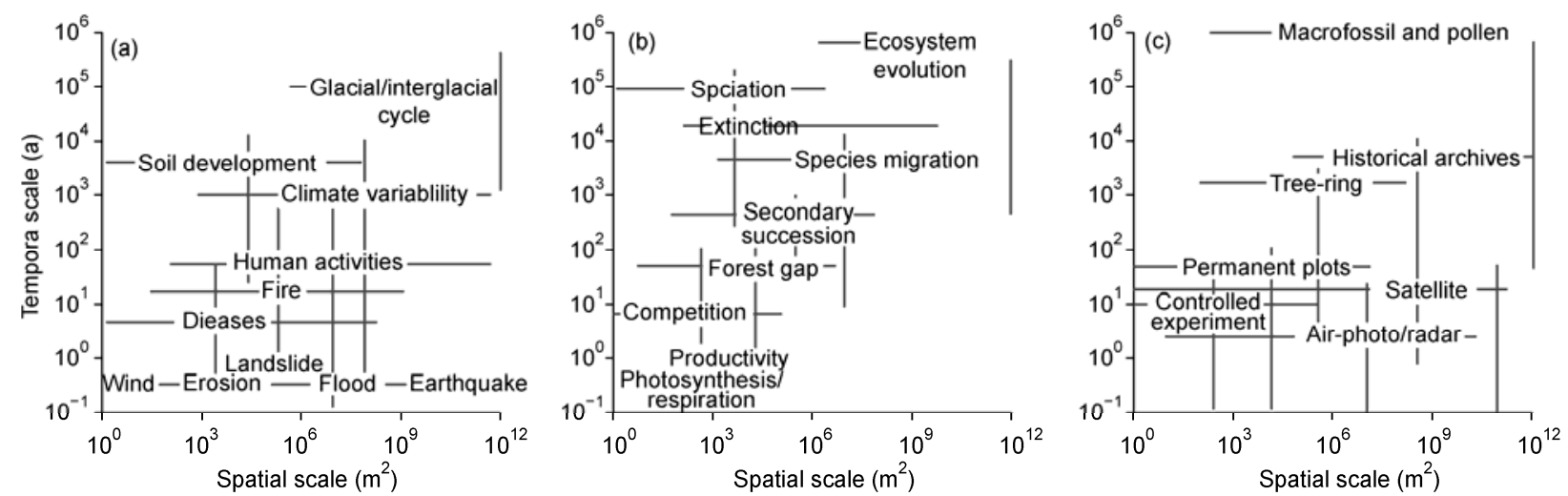

Figure 1 Dominant forcing (a), response mode (b) and research method (c) for vegetation dynamics at different spatial and temporal scales (modified from $[10,11])$. For details please refer to text. 
northern North America (e.g. Alaska) even during the Last Glacial Maximum (LGM) [20,21], suggesting that forest could inhabit high latitudes during the LGM under special topographical conditions [22]. Mountains in northern China, such as the Taihang Mountains, and the Greater Hinggan Mountain in the Changbai Mountains, were also suggested to be refuges for trees in the LGM period because of their topographic characteristics [23].

The above conclusions were drawn from a combination of paleoecological and genetic studies [21]. It can be difficult to identify exact locations for the occurrence of plant species because of the long distances over which pollen is transported. Mitochondrial DNA is maternally inherited and transmitted only through locally dispersed seed, and is thus able to indicate the local occurrence of plant species [21].

(2) Cycle of vegetation evolution at mid-latitudes. A circular evolution mode was first suggested for the evolution of climate, soil and vegetation for mid-latitudinal deciduous broadleaf forest regions in Europe and North America, with the following characteristics: (1) an initial increase in temperature followed by a gradual decrease during the transition from a glacial period to the peak of an interglacial period, (2) fresh soil changed from basic to acidic due to long-term nutrient leaching after glacier retreat, (3) the vegetation characteristics shifted from dominance by non shade-tolerant species to dominance by the shade-tolerance species, as represented in a four-stage-model dominated by birch, oak, pine and grassland in turn. Despite the differences in species composition between plant communities, the overall evolution process was similar in different regions $[24,25]$.

This cyclic pattern of evolution was validated by studies of vegetation evolution on sand soil in different regions of the globe, which showed that phosphorus leaching limited the development of forest soil in the sand [26]. Unlike nitrogen, which is regenerated biologically, phosphorus was unable to regenerate, and its loss from the soil led to a change in the proportion of bacteria and fungi in the soil, and eventually the effectiveness of the nutrients declined [26]. Increasingly severe nutrient limitation drove the replacement of broad-leaved forest by coniferous forest, and then by grassland [25].

However, the above model is only suitable for the humid climate region that has obvious temperature variations. Located in a water-stressed region, the vegetation succession pattern of the forest-steppe ecotone in north China during the Holocene also showed four stages dominated by birch, oak, pine and grass [27], but the mechanism of the evolution was not exactly the same as that of the above-mentioned vegetation cycles on sandy dunes. Control of hydrological and thermal conditions by the East Asian summer monsoon intensity was critical for vegetation evolution in China [28-30]. After the middle Holocene, vegetation susceptibility to precipitation change increased, while sensitivity to temperature was lost, leading to increased drought stress.
Due to the increase in drought severity, the dominance of oak was gradually replaced by more drought-tolerant pine species, which in turn were eventually replaced by the grassland vegetation [27]. Vegetation evolution during this period was relatively similar to vegetation changes driven by drought in other regions, such as the Mediterranean [31] and the African Sahel region [32].

(3) Individualistic response of different plant groups. Based on palynological research, Davis firstly suggested an individualistic response of plants to the past climate change [33]. Not only plant species, but also ecological species groups or plant functional groups (for example, trees and herbs) also showed similar patterns of response to past climate change [22]. Grassland vegetation responded rapidly whereas forest response was lagged, showing more stability and hysteresis in the forest relative to the grassland. The change in forest distribution was a slow process, due to the long life span of trees, whereas grassland distribution might show a rapid response due to the prevalence of annual and biennial grassland plants [10,22,33].

Individualistic responses of different plant groups mainly occurred in the transitional stages of climate. A review of Late Quaternary vegetation history in North America showed that different plant species responded to climate change individualistically at the millennial time scale. The distribution and composition of vegetation did not show evident change during the LGM (21000-17000 a BP) and the mid- to late-Holocene (7000-500 a BP), but in the lateglacial period and the early Holocene (16000-8000 a BP) and the most recent period, changes have been morre obvious. Changes in species distribution were mostly reflected by individualistic changes in species abundance and distribution. In addition to the northward movement of most species, there was also migration in the east-west direction [34]. Review of the Holocene vegetation evolution in China showed that changes in the composition and distribution of vegetation occurred mainly in the early Holocene when climate changed from cold to warm, and at about 4500 years BP when climate changed from wet to dry [30].

Individualistic responses of ecological species groups or plant functional types may lead to the extinction of some vegetation types present in the historical record. This community type, referred to as "no-analog" or "no-modernanalog", appeared in the transitional climate periods. The migration of some plant species was unable to keep up with fast climate change. Due to the different migration rates, the time lag between climate change and migration varied between species, and the plant community may have become restructured [35]. For instance, Fagus-Tsuga and PiceaAlnus-Betula appeared in the early Holocene in North America and still exist at present, while some forest types present in the late-glacial (such as Picea-CyperaceaeFraxinus-Ostrya/Carpinus) have disappeared [34].

(4) The cumulative effects of climate change and the lagged response of the vegetation. Forest showed a greater 
resistance to climate change. For short-term climate fluctuations, forest dynamics may be characterized by changes in growth, canopy density, and patch size. As a result of the existence of refuges and seed banks, the original vegetation types had strong flexibility and resilience, thereby resisting changes in vegetation types. Only in a quite long period of accumulation under the influence of climate processes, did the forest type ultimately change [36,37].

Due to the cumulative effects of climate change, there was commonly a time lag in the vegetation response. The length of the lag in some areas could reach hundreds of years, even one thousand years: for example, the first appearances of pioneer species and climax species in the plant community in the early Holocene differed by 4000 years or even longer [38]. Unstable climate in the early Holocene led to the blooming of pioneer species, while in contrast, climax species became established only when climate was relatively stable [38]. In the Sahel region in Africa, for example, while the climate drying trend has been gradual for nearly 6000 years, the forest was not replaced by grasslands until only about 4300 a BP [32]. It should be noted that forest fragments of low density or small size are sometimes undetectable by pollen evidence, so the time-lag may thus be overstated [39]. Instead of climatic stress, the wide expansion and retreat of forest may be related to strong disturbances, such as fire, pest attack and disease. In a sense, the lagged vegetation response may be due to the cumulative effects of climate change that have led to an increasing frequency of disturbances [40].

The time lag of vegetation response to climate change implies that vegetation and climate are not completely in equilibrium, and that vegetation response to climate change might not be linear, but rather controlled by some thresholds. If other biological and non-biological factors work together, inertia and irreversibility may have a control on the long-term response of vegetation to climate change [40].

\subsection{The role of environmental factors in the response of vegetation to climate change}

(1) Stress of climate factors. The impact of climate change on vegetation is mainly in the form of long-term stress. In periods with relatively stable climate, such as in the LGM and the mid-Holocene, climate was relatively stable, although vegetation had also been stressed by climate during these two periods. However, relative to the climate transitions, vegetation is more stable under a stable climate [29].

It has been argued that the current global pattern of vegetation is not dominated by the current climate pattern, but instead is determined by the amount of climate change since the Holocene [41,42], demonstrating the effects of the magnitude of climate change on species distribution. In the forest-steppe ecotone in north China, for example, larger interannual precipitation fluctuations provided less stable habitat conditions, allowing pioneer communities to exist for a long time because of their more competitive advantage over stable climax communities. This explained the longterm occurrence of birch forest as a pioneer community in this region since the start of the Holocene [43]. The longterm existence of the pioneer community could also improve the ability of regional vegetation to adapt to climate change. When climate changed quickly, fast-growing pioneer communities expanded rapidly, with a smaller migration distance, so the overall pattern of regional vegetation was characterized by the shifting of different forest types, while the distribution of forest boundaries might not have changed so clearly [38].

(2) The buffering effect of non-climatic factors. On the global or regional scale, climate change has been commonly regarded as critical to vegetation dynamics. But on a regional scale, environmental factors other than climate, such as soil, topography, biology and human activity, and many other factors, have also affected vegetation, and further led to the nonlinear response of vegetation to climate change.

Plant growth mainly depends on soil water and nutrients. In different parts of the world, the soil water and nutrients affect the dynamics of vegetation in different ways. On the other hand, soil development is also affected by vegetation dynamics at millennial time scales [44]. In areas with strong soil water fluctuations, such as in the boreal zone, the inland arid areas and alpine regions, vegetation dynamics are most vulnerable to the influence of soil moisture. The extensive distribution of wetland ecosystems determined microclimate in the boreal zone and prevented climate warming from melting of the permafrost, so that the relationship between melting of permafrost and climate warming become very complicated [45]. Influenced by complicated spatio-temporal patterns of the thawing permafrost, the forest-prairie ecotone in the north of the Great Plains of North America has experienced frequent changes, especially changes in the proportion of forest and grassland at the local scale [44]. In arid areas, vegetation degradation has accelerated soil erosion, and loss of the fine particles in the soil has altered soil permeability and water retention ability, and reduced the effectiveness of the nutrients in the soil [46]. In the forest-steppe ecotone of north China, soil desertification and the vegetation coverage decline often covaried [47]. Alpine soil development was usually very weak, and the soil water retention ability was poor. Although climate warming benefited the upward movement of the upper timberline, the lack of available soil moisture might have caused a delay in vegetation response to climate change. Similarly, in east Switzerland, Norway spruce settled after suitable climatic conditions had prevailed for 3000 years, while in the west Switzerland the time lag reached 6000 years [48].

Complicated topographical conditions created diverse local microenvironments through the redistribution of precipitation, radiation, wind activity, soil properties, and water vapor transmission [49]. In this mosaic of various habitat types at the regional scale, some served as a refuge for spe- 
cific vegetation types under rapid climate change, allowing them to survive through the extreme climate period. With subsequent climate amelioration, short distance seed dispersion from the refuge and fast vegetation succession created a topography-controlled mosaic pattern of vegetation patches with strong resistance and stability to climate change.

Biological interactions contributed to vegetation evolution mainly by influencing the germination, establishment and interspecies competition and plant community succession. Animals were the main carrier of plant propagules, for example nuts of oak (Quercus) and hazelnut (Corylus), and of selected plant species through the ingestion of their propagules [50]. Accidental events in the past were suspected to cause the migration of nut trees from south to north: for example, nuts of North American beech (Fagus sylvatica) were carried over the great lakes by birds [10]. Climate change drove the migration of animals, which further led to the spread of the plant seeds they liked to eat. However, this has been doubted in recent studies. It has been argued that plant propagules were preserved in areas covered by ice during the ice age. Due to rising temperatures and melting glaciers in the late-glacial, the sprouting propagules of plants formed new individuals within a short period. The south to north migration of plants as indicated by pollen evidence could actually be a result of the eventual germination and establishment of formerly ice-covered propagules exposed by glacial retreat [40]. Animal populations also play an important role in maintaining vegetation structure, for example the reduction of the number of animals in the forests may affect the shifting of the oak forest to beech forest in Europe [51].

In summary, the buffering effect of non-climatic factors was negligible at the regional scale, as was also demonstrated by forest relicts in some specific habitats [27]. The different mechanisms of non-climatic factors should be stressed: while the little-changing topographical factors regulated vegetation dynamics with negligible feedback, interactions between plants and animals, and between vegetation and soil, have always been shifting.

(3) Disturbance events. Relative to the long-term stress from climate, disturbance events have been one of the direct causes of the rapid changes of vegetation distribution. Fire, plant diseases and insect pests all affect the distribution of the forest.

During climate deterioration, plant diseases and pest attacks occurred readily, which resulted in the degradation and even disappearance of forest [52]. A large number of examples have shown that plant diseases and pests have been the direct cause of large-scale forest recession, such as the elm decline 5000 years ago in Europe [53]. Fungi and insect dynamics, on the other hand, could have a positive influence on vegetation. Propagules of plant species reached the bare land after glacier retreat, relying on the early arrival of fungi to absorb arid soil nutrients [54]. The relationship between the species migration and fungi has also been confirmed by modern ecological evidence [55]. Phenological changes caused by climate change may have had an important impact on insect pollination [56].

Fire is the product of climate drying, but the outbreak of fire also needs vegetation that can provide enough fuel. A large number of instances show that the fire was the direct cause of vegetation advance and retreat. A climate-fuel-fire cycle model has allowed the Holocene vegetation to maintain the forest-prairie ecotone in the northern Great Plains of North America for a long time period. The cycle of forestor prairie-dominance has been sustained for 160 years. When the climate was dry, the vegetation was dominated by grassland rich in fuel; the greater frequency of fire in turn cleared grassland and contributed to the spread of the forest [57].

Due to the different roles of climatic factors, nonclimatic factors and disturbance events, the forest distribution did not shift completely synchronously with climate change and instead showed a nonlinear response: when the climate changed, vegetation composition did not quickly reach equilibrium with the new climate conditions. Affected by non-climatic factors, the response of vegetation to climate change showed stages of change related to temporal and spatial scales. Although extreme events could lead to the growth, decline or even death of a plant, regional forest dynamics might have been characterized by patch dynamics for a longer time scale due to regional topography and soil buffering, and the existence of relict forest patches, germination of the originally retained seed, and effects of various biological factors. The shift of forest boundaries over a larger area scale required larger and more frequent disturbance events that occurred only under long-term climate trends.

\subsection{Is the current climate change altering the distribu- tion of the forest?}

Transitional vegetation types or the transitional zone of different vegetation types are most sensitive to climate change, so the current expansion and shrinkage of forest due to climate change is mainly concentrated in the transitional zone.

Although there are a large number of reports about the upward movement of the alpine timberline and northward movement of the Arctic timberline [58], these results were not free from the influence of their sampling methods. The sample-total method showed that there has been no increase in the alpine timberline on the southeastern Tibetan Plateau during the past one hundred years [59]. Based on North American forest survey data analysis, it was also found that in North America, the main tree species did not move northward with climate warming [13]. Compared with the previous selective sampling approach [60], the above research based on the sampling-total method provided an accurate age structure of the plot, therefore it was more relia- 
ble for examining changes in forest distribution.

The prairie zone of North America, and other regions dominated by grassland, were invaded by woody plants [61] However, a review of previous reports of forest die-off indicated an opposite trend, whereby forest decline and die-off mostly occurred in the forest-grassland transitional zone [62]. The invasion of grassland by woody plants was mainly related to overgrazing, while forest die-off near the dry timberline was mainly the product of climate drying [63]. There was, however, no evidence that long-term climate stress directly led to a visible change of forest distribution $[64,65]$.

\section{Prediction of the future forest distribution}

\subsection{Main approaches to predicting the future forest distribution}

Conventional studies of vegetation geography have mainly focused on forecasting of the Potential Natural Vegetation (PNV), according to the current climate, soil, landforms, vegetation characteristics and succession rule of vegetation, to infer the future development of vegetation [65,67]. In recent years, with the deepening understanding of future climate change, vegetation dynamics predictions for the future have gradually shifted towards vegetation dynamics driven by climate change in different future climate change scenarios.

The study of past analogs is one way to predict future forest distribution. It has been commonly accepted that forest distribution during the mid-Holocene dry period can be used as analog of warming-induced forest distribution in the future [68].

Space-for-time-substitution is another commonly used approach. It uses the current vegetation present in warmer areas as an indication of the future vegetation under climate warming, equivalent to a displacement in the vegetationclimate diagram [69]. The conventional model of biogeography was in fact a space-for-time-substitution approach [70,71].

During recent years, mechanism models such as Dynamic Global Vegetation Models (DGVMs) integrating a biological geography model and biogeochemical model have been established. These reflect the forest-gap model of plant community succession and have drawn increasing attention. These models use plant functional groups to indicate regional vegetation composition, through modeling the climate limits of a proportion of plant functional groups to assess vegetation dynamics. The Lund-Potsdam-Jena model is the most commonly used DGVM for predicting vegetation distribution changes [72,73].

As yet there has been very limited work on the reconstruction of past forest distribution or the prediction of future forest distribution at the global and regional scales. Prentice et al. reconstructed forest distribution at the global and regional scales using the BIOME model [74], but the reconstruction was limited to the Last Glacial (18 ka BP) and the mid-Holocene Megathermal (6 ka BP) owing to a data shortage (Figure 2(a)). The statistical relationship between pollen composition and vegetation types was adopted in this model, therefore this method essentially adopted the modern analogy method. Compared with the current forest distribution, there were more forests distributed during the Holocene Megathermal in northern high latitudes, central and western regions of North America, and North Africa. A simulation using the LPJ-DGVM forecasted that future changes in the forest distribution will be concentrated in the high latitudes, where there will be a northward spread, but with no significant change in the low latitudes [75] (Figure 2(b)). At the regional scale, the simulation results varied among different models.

\subsection{The limitations of future predictions based on modern analogs}

Although past and future climate changes may share similar magnitudes, there are still deficiencies in the use of past climates as analogs for the future. The rate of climate change caused by rising concentrations of greenhouse gases might be higher than that during any period of the Holocene [78]. In addition, modern human activities lead to environmental pollution and landscape fragmentation, which are regarded as new disturbances. All these bring greater uncertainty into the future global change predictions [1].

Simply using the temperature analogy for the prediction of future forest distribution ignores the role of factors other than temperature on vegetation dynamics. In the interior of the Great Plain region of North America, past environmental change was totally different from that of modern times because of the larger difference in insolation between summer and winter, the effect of the Laurentide ice sheet and the influence of dry lake Agassiz. During the Holocene, the local scale vegetation response factors strongly affected the initiation time and rate of climate drying at a specific location, and only a third of the samples showed a prompt response to climate drying [80]. Therefore, it was reasonable to suspect that due to the combination of different environmental factors it is not necessarily possible to find an analogy from the past to predict the vegetation in the future.

Paleoecological evidence has shown that disturbance events have commonly been the determinant of the changing forest distribution. However, disturbance events in the past varied with climate pattern (such as seasonal differences) and human activities, so it is unreasonable to use the past to predict future changes. In northern Minnesota, USA, the mid-Holocene (about 8000-4000 a BP) experienced obvious climate drying. However, the vegetation response and climate drying were not synchronous [81]. In the later Middle Holocene, while soil moisture was increasing, prairie remained the dominant landscape type, likely owing to 

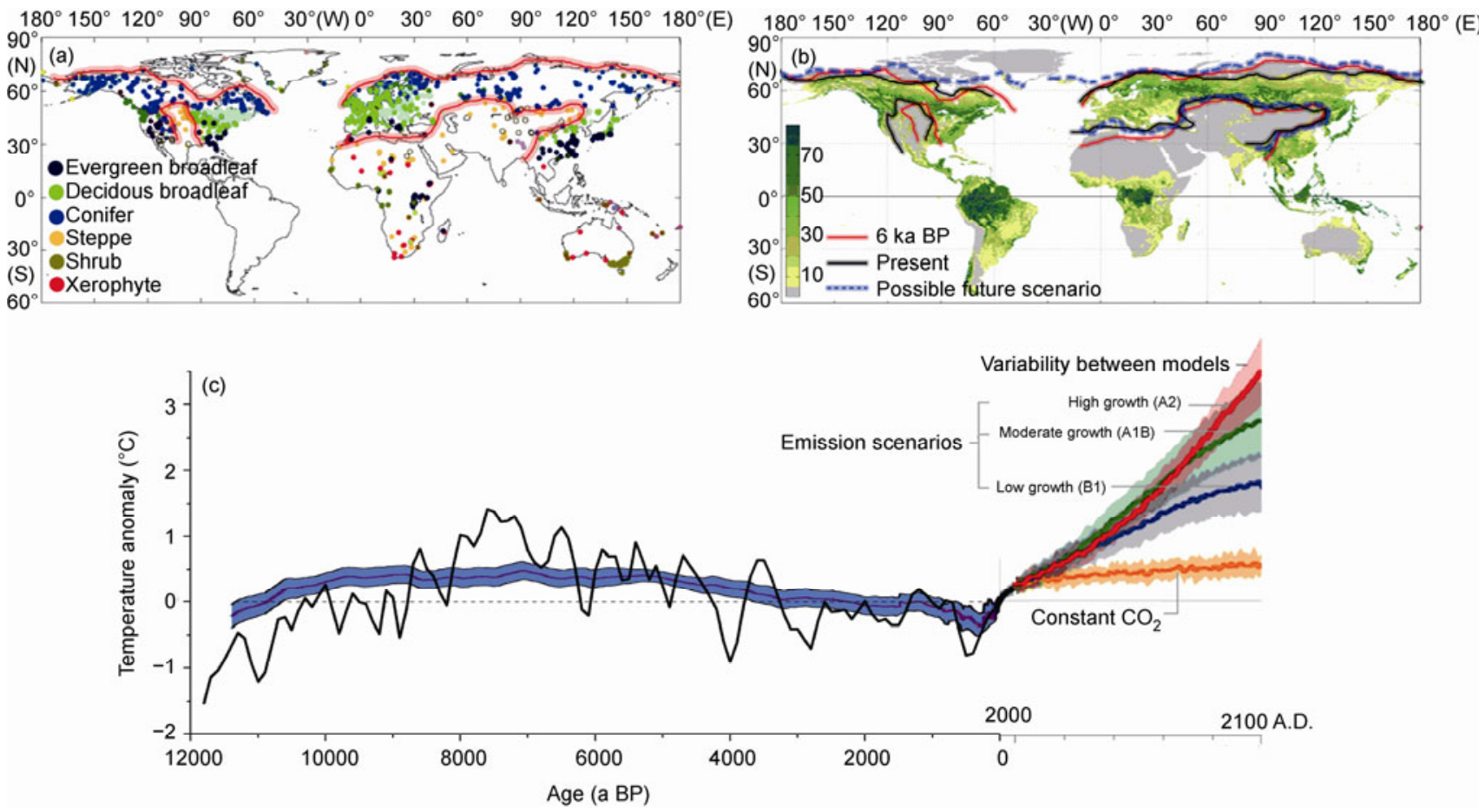

Figure 2 The temperature of the past, present and future, and the change in forest distribution. (a) The distribution of global forest reconstructed from the sediment pollen assemblages [73]. The scope of the red line represents the forest distribution, this is not marked in the southern hemisphere due to a lack of data. (b) The distribution of forest in the past, present and future in the northern hemisphere. Past vegetation boundaries follow those in (a). The modern forest distribution is from remote sensing data [76,77], the different colors indicate different types of forest coverage; the future forest distribution LPJ model simulation was presented after [75]. (c) Temperature anomaly of the entire world and in China relative to the 1961-1990 temperature, and future climate predictions based on models [78]. The blue shadow area shows the global average [17], and black lines show China's regional Holocene temperature change [17]. It is predicted that the temperature in 2100 may be higher than that during any period of the Holocene epoch [17].

the limitation of forest expansion by high fire frequency. The asynchronous response of vegetation to climate change showed that using the mid-Holocene vegetation conditions as a proxy for the response of vegetation to future climate warming was likely to have a large uncertainty, due to the lack or complete absence of fire at present [82].

"No modern-analogs" implies that future vegetation might be totally different from that in modern times, and movement of the forest boundary is only one of the possible responses of vegetation to climate change. Savannification with decline in forest cover is another possibility [83]. Individualistic responses of plant species to climate change could lead to changes in the vegetation composition, but may mask climate change signals in the vegetation structure.

\subsection{The limitations of space-for-time-substitution}

Space-for-time-substitution is a simple extrapolation based on the current vegetation-climate relationships. The current hydrological and thermal conditions are used to describe the modern vegetation distribution, then predict vegetation change by using these conditions as model input [84]. This kind of empirical biogeographical model was established based on four assumptions: first, vegetation and plant species are in equilibrium with the present climate and will remain so in the future; second, the relationship between vegetation and climate would not alter with climate change; third, the selected climatic variables were considered to be deterministic with respect to the vegetation distribution, and no other variables were taken into consideration; fourth, the ecological niche of species was set as constant. Box first developed a quantitative model for terrestrial vegetation distribution at a global scale by dividing global plants into 41 life forms and choosing eight predictable climate variables (average temperature, mean monthly temperature of the warmest month, annual average temperature, annual rainfall, annual humidity index, highest monthly average precipitation, mean monthly precipitation, and the average rainfall of the warmest month) [70]. The model was validated and simulated for 65 single locations. The model has been further improved through many single point simulations: for example, Emanuel divided the Holdridge life zone [85] according to the global climate data of 8000 stations, and predicted a $37 \%$ and $32 \%$ reductions in the areas of coniferous forest and tundra, respectively, and an increase in the area of grassland under future climate warming [71].

Although it is easily to operate to models of vegetation distribution and predict changes based on hydrological and thermal conditions, this approach has obvious limitations: first of all, only a small number of indicators (such as temperature and annual precipitation) were used to describe 
large scale vegetation landscapes, and it was thus hard to describe complicated regional vegetation pattern and process, especially the relationship between extreme climate events and vegetation patterns that have so for been not very clear [86]. Second, from the perspective of the process of vegetation evolution, the current hydrological and thermal conditions are unable to fully describe the vegetation distribution pattern because of the buffering of non-climatic factors, especially in the arid regions. Most vegetation types use water directly from the soil [87]. Besides being subject to precipitation, soil moisture content is influenced by factors such as soil texture and topography [88,89]. For the tree-grass coexistence in the tropical savannahs, the trees mainly absorb water from the lower soil layer whereas herbs absorb water from the upper soil layer, known as the "two layer model" of soil water use [90,91]. Third, plant growth and reproduction are biological process regulated by biotic factors as well in addition to climatic factors Due to the lifespan of the forest of hundreds of years, there has so far been no suitable indicator that covers the complicated dynamic process. The hydrological-thermal conditions are unable to represent the succession processes of vegetation; for example, the overlap in the distribution of pioneer species and climax species cannot be represented solely by climatic factors. In northern China, birch (Betula platyphylla) and oak (Quercus spp.) forests usually overlapped their climate niches [80]. Also, the location of relic plant communities in the vegetation-climate diagram might beyond the normal ranges for their types, such as relic forests on sandy dunes in the Inner Mongolia grassland [43]. Finally, species' real niches been changing since the Holocene, while in contrast the fundamental niches have been remained constant [84].

Past studies often linked the boundaries of different vegetation types to climate limits, and have tried to use a particular climate threshold to indicate the distribution of vegetation boundaries: for example, the annual rainfall of 400 $\mathrm{mm}$ was often thought to be boundary between humid and arid climates, as well as the boundary between the forest and steppe distribution. Because the polar timberline and alpine timberline are limited by temperature, some warmth indices have been used to indicate the position of the timberline, for example the highest monthly average temperature's $10^{\circ} \mathrm{C}, 11^{\circ} \mathrm{C}$ or $12^{\circ} \mathrm{C}$ isotherm, or the daily highest temperature's $15^{\circ} \mathrm{C}$ isotherm for the warmest month, or a frost-free period of 90 days [92]. For both the forest-steppe ecotone and the alpine/polar timberline, these indicators only roughly indicated timberline position. Under the effects of topography, soil, and the influence of different plant competition between groups, as well as the feedback of local microclimate on vegetation, the timberline usually shows a wide or narrow ecological transition zone instead of a line [94]. In addition, there are very few meteorological stations located in timberline areas, such that climate indicators near the timberline have commonly been interpolated using a temperature lapse rate, yet the complicated pattern of microclimates near the timberline is hard to be model [95].

\subsection{Problems and challenges of dynamic vegetation models}

DGVMs developed during the last 20 years have taken into consideration the main processes of vegetation dynamics, fire disturbance and the different responses of plant functional groups to the climate change [72,73]. Simulation results by LPJ-DGVM showed that, under the scenarios of future climate change, showed the forest distribution did not decline or expand widely, and instead the changes were indicated by growth (such as the increase of biomass), and tree species replacement (such as the deciduous species replaced by evergreen trees) and so on [75]. While the DGVMs were more reliable than empirical biogeography model, there were still the following limitations:

First, the DGVMs were established assuming a vegetation-climate equilibrium [72]. As a matter of fact, the vegetation-climate equilibrium required the rate of vegetation change to match that of the climate change [96]. A prediction of boreal forest showed that, if forest vegetation and climate were in equilibrium, the rate of northward movement of coniferous forest should be up to $17-50 \mathrm{~km}$ per decade, far higher than the rate of $1-4.5 \mathrm{~km}$ per decade during the Holocene [96,97]. Past forecasts did not consider the time-lag of vegetation response to climate change, or set a fixed time-lag, while in practice the time lag varies between different plant groups [96].

Second, the DGVMs classified plant functional types according to their adaptation to environmental conditions (especially the climatic conditions). At global scales these groups are typically deciduous conifer, evergreen conifer, tree evergreen hardwood, deciduous hardwood, C3 herb, and C4 herb [98]. This classification has mainly considered the adaptation of plants to climate, however, without considering the succession relationships. For example, birch and oak belong to the same functional type, but birch appeared at the earlier stage of succession, while oak appeared at the later stage of succession.

Third, although the DGVMs belong to the process class of models, they have only established a few climate thresholds in vegetation dynamics. The LPJ model, for example, treated the soil as having two layers and 9 types all over the world, and parameterized the penetration rate and root distribution proportion for the two layers of each type [72]. In addition, vegetation succession was not considered in the model. In fact, pioneer species that can rapidly invade new habitat may not be able to exist for a long time, while climax species often take much longer to enter a new habitat [38].

In summary, the prediction of vegetation response to future climate change has been far from adequate when con- 
sidering the openness of the vegetation system and the complexity of the relationship between vegetation and climate. Process-based models of vegetation dynamics are effective at predicting future vegetation dynamics. Based on the research achievements of studies predicting forest response to past climate change, and the complexity of the current relationship between vegetation and climate, the development of process-based models should proceed in the following directions, which should also be the focus of future research.

(1) Integrating different spatial and temporal scales: different driving forces and response modes of vegetation dynamics operate at different scales of space and time [10]. Most process-based models for vegetation dynamics have been designed at a global scale rather than regional or local scale. We suggest that incorporating driving forces and response modes at different spatial and temporal scales in models, and expanding single level models to multi-level models, should be the directions of future model development [99].

(2) Considering the complexity of climate change: in predictions of the future, the complexity of climate change, such as climatic seasonality, has rarely been considered. Climate thresholds for vegetation response have been much simplified and thus need to be improved in subsequent model development [80].

(3) Considering the effect non-climatic factors: the buffering effect of topography, soil characteristics and biological factors are one of the reasons for a time-lag in vegetation response to climate change, but the buffer effect has been considered only in the local scale models, and needs to be incorporated into regional or global scale models [100].

(4) Considering the forest distribution-climate change feedback: the vegetation distribution pattern, especially the distribution of forest, feeds back into climate change [101]; however, at present the feedback mechanism and patterns are still being explored [102]. This feedback needs to be reflected in future models.

(5) Including human modification on vegetation: when predicting the response of vegetation dynamics to future climate change, we must be aware that almost all vegetation has been modified by human activities. Human activities have not only transformed the structure of the vegetation, but have also regulated disturbance events that are critical to vegetation dynamics, for instance, intentional or unintentional fires started by humans in the past have caused changes in vegetation composition and structure. The response of vegetation to both strong human influence and climate change is still worth studying.

\section{Conclusions}

A review of vegetation responses to past climate change has shown that vegetation (especially forest) responds to cli- mate change in a nonlinear manner. Due to the openness of the vegetation system, a combination of biological factors and non-biological factors pushes the relationship between vegetation and climate far from its equilibrium. The three main approaches to vegetation distribution predictions have been established assuming an equilibrium relationship between vegetation and climate. As improved forms of empirical biogeography models, DGVMs have incorporated the main vegetation dynamic processes, fire, and the response modes of different plant functional groups to climate change, but still need to take into account recent achievement in both paleoecological and modern ecological research. Spatial and temporal scales, the complexity of climate change, the role of factors other than climate, the feedback between forest distribution and climate change, and human regulation of disturbance events should all be incorporated into future models.

This work was supported by the National Natural Science Foundation of China (41071124 and 31021001).

1 Bonan, G B. Forests and climate change: Forcings, feedbacks, and the climate benefits of forests. Science, 2008, 320: 1444-1449

2 Pan Y, Canadell J G, Ciais P, et al. A large and persistent carbon sink in the world's forests. Science, 2011, 333: 988-993

3 Gerten D, Schaphoff S, Haberlandt U, et al. Terrestrial vegetation and water balance-hydrological evaluation of a dynamic global vegetation model. J Hydrol, 2004, 286: 249-270

4 Claussen M. Late Quaternary vegetation-climate feedbacks. Clim Past, 2009, 5: 203-216

5 Harris J A, Hobbs R J, Higgs E, et al. Ecological restoration and global climate change. Restor Ecol, 2006, 14: 170-176

6 Zhang P, Shao G, Zhao G, et al. China's forest policy for the 21st century. Science, 2000, 288: 2135-2136

7 Petit R J, Hu F S, Dick C W. Forests of the past: a window to future changes. Science, 2008, 320: 1450-1452

8 Spellerberg I A, Sawyer J W D. An Introduction to Applied Biogeography. Cambridge: Cambridge University Press, 1999

9 Whittaker R J, Araújo M B, Jepson P, et al. Conservation biogeography: Assessment and prospect. Divers Distrib, 2005, 11: 3-23

10 Delcourt H R, Delcourt P A. Quaternary Ecology: A Palaeoecological Perspective. London: Chapman and Hall, 1991

11 Walker L R, del Moral R. Primary Succession and Ecosystem Rehabilitation. Cambridge: Cambridge University Press, 2003

12 Bertrand R, Lenoir J, Piedallu C, et al. Changes in plant community composition lag behind climate warming in lowland forests. Nature, 2011, 479: 517-520

13 Zhu K, Woodall C W, Clark J S. Failure to migrate: Lack of tree range expansion in response to climate change. Glob Chan Biol, 2012, 18: $1042-1052$

14 Zhao X, Zhou D, Fang J. Satellite-based studies on large-scale vegetation changes in China. J Integr Plant Biol, 2012, 54: 713-728

15 Swetnam T W, Betancourt J L. Mesoscale disturbance and ecological response to decadal climatic variability in the American Southwest. In: Stoffel M, Bollschweiler M, Butler D, et al. eds. Tree Rings and Natural Hazards. Berlin-Heidelberg: Springer, 2010. 329-359

16 Liu H. Quaternary Ecology and Global Change (in Chnese). Beijing: Science Press, 2002

17 Marcott S A, Shakun J D, Clark, P U, et al. A reconstruction of regional and global temperature for the past 11300 years. Science, 2013, 339: 1198-1201

18 Birks H J B. Holocene isochrone maps and patterns of tree-spreading 
in the British isles. J Biogeog, 1989, 16: 503-540

19 King G A, Herstrom A A. Holocene tree migration rates objectively determined from fossil pollen data. In: Huntley B, ed. Past and Future Rapid Environmental Change: The Terrestrial and Evolutionary Processes of Terrestrial Biota. Berlin-Heidelberg: Springer Verlag, 1997

20 Parducci L, Jørgensen T, Tollefsrud M. Glacial survival of boreal trees in northern Scandinavia. Science, 2012, 335: 1083-1086

21 Hu F S, Hampe A, Petit R J. Paleoecology meets genetics: Deciphering past vegetational dynamics. Front Ecol Environ, 2009, 7: 371379

22 Stewart J R, Lister A M, Barnes I, et al. Refugia revisited: Individualistic responses of species in space and time. Proc R Soc Bio Sci, 2009, 277: 661-671

23 Qiu Y, Fu C, Comes H P. Plant molecular phylogeography in China and adjacent regions: Tracing the genetic imprints of Quaternary climate and environmental change in the world's most diverse temperate flora. Molec Phylogen Evol, 2011, 59: 225-244

24 Iversen J. The bearing of glacial and interglacial epochs on the formation and extinction of plant taxa. Uppsala Univ Arssk, 1958, 6: 210-215

25 Birks H J B, Birks H H. The rise and fall of forests. Science, 2004 , 305: 484-485

26 Wardle D A, Walker L R, Bardgett, R D. Ecosystem properties and forest decline in contrasting long-term chronosequences. Science, 2004, 305: 509-513

27 Liu $\mathrm{H}, \mathrm{Xu} \mathrm{L}$, Cui H. Holocene history of desertification along the woodland-steppe border in northern China. Quat Res, 2002, 57: 259-270

28 Dykoski C A, Edwards R L, Cheng H, et al. A high-resolution, absolute-dated Holocene and deglacial Asian monsoon record from Dongge Cave, China. Earth Planet Sci Lett, 2005, 233: 71-86

29 Zhao Y, Yu Z, Chen F, et al. Vegetation response to Holocene climate change in monsoon-influenced region of China. Earth Sci Rev, 2009, 97: 242-256

30 Zhao Y, Yu Z. Vegetation response to Holocene climate change in East Asian monsoon-margin region. Earth Sci Rev, 2012, 113: 1-10

31 Carrión J S, Munuera M, Dupré M, et al. Abrupt vegetation changes in the Segura Mountains of Southern Spain throughout the Holocene. J Ecol, 2001, 89: 783-797

32 Kropelin S, Verschuren D, Lézine A, et al. Climate-driven ecosystem succession in the Sahara: The past 6000 years. Science, 2008, 320: 765-768

33 Davis M B. Climatic instability, time lags, and community disequilibrium, In: Diamond J, Case T J, eds. Community Ecology. New York: Harper and Row, 1986. 269-284

34 Williams J W, Shuman B N, Web III T, et al. Late-Quaternary vegetation dynamics in North America: Scaling from taxa to biomes. Ecol Monog, 2004, 74: 309-334

35 Williams J W, Shuman B N, Webb III T. Dissimilarity analyses of Late-Quaternary vegetation and climate in eastern North America. Ecology, 2001, 82: 3346-3362

36 Araújo M B, Pearson R G. Equilibrium of species' distributions with climate. Ecography, 2005, 28: 693-695

37 Moss R H, Edmonds J A, Hibbard K A, et al. The next generation of scenarios for climate change research and assessment. Nature, 2010, 463: 747-756

38 Cole K L, Vegetation response to early Holocene warming as an analog for current and future Changes. Conserv Biol, 2009, 24: 29-37

39 Giesecke T, Hickler T, Kunkel T, et al. Towards an understanding of the Holocene distribution of Fagus sylvatica L. J Biogeog, 2007, 34: 118-131

40 Miller P, Giesecke T, Hickler T, et al. Exploring climatic and biotic controls on Holocene vegetation change in Fennoscandia. J Ecol, 2008, 96: 247-259

41 Araújo M B, Nogués-Bravo D, Diniz-Filho J A F, et al. Quaternary climate changes explain diversity among reptiles and amphibians. Ecography, 2008, 31: 8-15

42 Sandel B, Arge L, Dalsgaard B, et al. The influence of Late Quaternary climate-change velocity on species endemism. Science, 2011,
33: 660-664

43 Liu $\mathrm{H}$, Cui H, Yu P, et al. The origin of remnant forest stands of $\mathrm{Pi}$ nus tabulaeformis in southeastern Inner Mongolia, China. Plant Ecol, 2002, 158: 139-151

44 Ewing $\mathrm{H}$ A. The influence of substrate on vegetation history and ecosystem development. Ecology, 2002, 83: 2766-2781

45 Camill P, Clark J S. Long-term perspectives on lagged ecosystem responses to climate change: Permafrost in boreal peatlands and the grassland/woodland boundary. Ecosystems, 2000, 3: 534-544

$46 \mathrm{He} \mathrm{N}, \mathrm{Wu} \mathrm{L}$, Wang Y, et al. Changes in carbon and nitrogen in soil particle-size fractions along a grassland restoration chronosequence in northern China. Geoderma, 2009, 150: 302-308

47 Yin Y, Liu H, He S, et al. Patterns of local and regional grain size distribution and their application to Holocene climate reconstruction in semiarid Inner Mongolia, China. Palaeogeogr Palaeoclimatol Palaeoecol, 2011, 307: 168-176

48 Gehrig-Fasel J, Guisan A, Zimmermann N E. Tree line shifts in the Swiss Alps: Climate change or land abandonment? J Veget Sci, 2009, 18: 571-582

49 Sherrer D, Körner Ch. Topographically controlled thermal-habitat differentiation buffers alpine plant diversity against climate warming. J Biogeog, 2011, 38: 406-416

50 Gill J L, Williams J W, Jackson S T, et al. Pleistocene megafaunal collapse, novel plant communities, and enhanced fire regimes in North America. Science, 2009, 326: 1100-1103

51 Lang, G. Quatäre Vegetaionsgeschichte Europas. Gustav Fischer Verlag, Jena, 1994

52 Motz J E, Morgan A V. Holocene paleoclimate and paleoecology determined from fossil Coleoptera at Brampton, Ontario, Canada. Canadian J Earth Sci, 2001, 38: 1451-1462

53 Girling M A. The bark beetle Scolytus scolytus (Fabricius) and the possible role of elm disease in the early Neolithic. In: Jone M, ed. Archaeology and the Flora of the British Isles. Oxford: Oxford University Committee for Archaeology Monograph, 1988, 14: 34-38

54 Wilkinson D M. Mycorrizal fungi and Quaternary plant migrations? Glob Ecol Biogeog Lett, 1998, 7: 137-140

55 Nunez M A, Horton T R, Simberloff D. Lack of belowground mutualisms hinders Pinaceae invasions. Ecology, 2009, 90: 2353-2359

56 Fabina N S, Abbott K C, Gilman R T. Sensitivity of plant-pollinatorherbivore communities to changes in phenology. Ecol Model, 2010, 221: 453-458

57 Brown K J, Clark J S, Grimm C, et al. Fire cycles in North American interior grasslands and their relation to prairie drought. Proc Natl Acad Sci USA, 2005, 102: 8865-8870

58 Walther G R, Post E, Convey P, et al. Ecosystem response to recent climate change. Nature, 2002, 416: 389-395

59 Liang E, Wang Y, Eckstein D, et al. Little change in the fir tree-line position on the southeastern Tibetan Plateau after 200 years of warming. New Phytol, 2011, 190: 760-769

60 Wang T, Zhang Q, Ma K. Treeline dynamics in relation to climatic variability in the central Tianshan Mountains, northwestern China. Glob Ecol Biogeog, 2006, 15: 406-415

61 Van Auken O W. Causes and consequences of woody plant encroachment into western North American grasslands. J Environ Manage, 2009, 90: 2931-2942

62 Allen C D, Hogg E H, Gonzalez P, et al. A global overview of drought and heat-induced tree mortality reveals emerging climate change risks for forests. Forest Ecol Manage, 2010, 259: 660-684

63 Williams A P, Allen C D, Macalady A K, et al. Temperature as a potent driver of regional forest-drought stress and tree mortality. Nat Clim Chan, 2013, 3: 292-297

64 Ciais P, Reichstein M, Viovy N, et al. 2005 Europe-wide reduction in primary productivity caused by the heat and drought in 2003. Nature, 2005, 437: 529-533

65 Liu G, Liu H, Yin Y. Global patterns of NDVI-indicated vegetation extremes and their sensitivity to climate extremes. Enviorn Res Lett, 2013, 8: 025009

66 Chiarucci A, Araújo M B, Decocq G, et al. The concept of potential natural vegetation: An epitaph? J Veget Sci, 2010, 21: 1172-1178 
67 Loidi J, Fernández-González F, Palmer M. Potential natural vegetation: Reburying or reboring? J Veget Sci, 2012, 23: 596-604

68 Fox D. Back to the no-analog future. Nature, 2007, 316: 823-824

69 Hendersen-Sellers A. Global terrestrial vegetation "prediction": The use and abuse of climate and application models. Prog Phys Geog, 1994, 18: 209-246

70 Box E O. Predicting physiognomic vegetation types with climate variables. Vegetatio, 1981, 45: 127-139

71 Emanuel W R, Shugart H H, Stevenson M P. Climatic change and the broad-scale distribution of terrestrial ecosystem complexes. Clim Chan, 1985, 7: 29-43

72 Sitch S, Smith B, Prentice I C, et al. Evaluation of ecosystem dynamics, plant geography and terrestrial carbon cycling in the LPJ dynamic global vegetation model. Glob Chan Biol, 2003, 9: 161-185

73 Prentice I C, Bondeau A, Cramer W, et al. Dynamic global vegetation modeling: quantifying terrestrial ecosystem responses to largescale environmental change. In: Canadell J G, Pataki D E, Pitelka L T, eds. Terrestrial Ecosystems in a Changing World. Berlin-New York: Springer, 2007. 175-192

74 Prentice I C, Jolly D, BIOME 6000 Participants. Mid-Holocene and glacial-maximum vegetation geography of the northern continents and Africa. J Biogeog, 2000, 27: 507-519

75 Lucht W, Schaphoff S, Erbrecht T, et al. Terrestrial vegetation redistribution and carbon balance under climate change. Carb Balan Manag, 2006, 1: doi:10.1186/1750-0680-1-6

76 DeFries R, Hansen M, Townshend J, et al. A new global 1-km dataset of percentage tree cover derived from remote sensing. Glob Chan $\mathrm{Bi}$ ol, 2001, 6: 247-254

77 Hansen M, Townshend J, DeFries R, et al. Estimation of tree cover using MODIS data at global. continental and regional/local scales. Int J Rem Sens, 2005, 26: 4359-4380

78 IPCC. Climate Change 2007: The Physical Science Basis. Contribution of Working Group I to the Fourth Assessment Report of the Intergovernmental Panel of Climate Change. Geneva: IPCC, 2007

79 Fang X, Hou G. Integrated reconstruction of Holocene temperature series in China (in Chinese). Chin Geog Sci, 31: 385-393

80 Williams J W, Shuman B N, Bartlein P J. Rapid responses of the prairie-forest ecotone to early Holocene aridity in mid-continental North America. Glob Planet Chan, 2009, 66: 195-207

81 Williams J W, Shuman B N, Webb III T. Dissimilarity analyses of Late-Quaternary vegetation and climate in eastern North America. Ecology, 2001, 82: 3346-3362

82 Umbanhowar C E Jr, Camill P, Geiss C E, et al. Asymmetric vegetation responses to mid-Holocene aridity at the prairie-forest ecotone in south-central Minnesota. Quat Res, 2006, 66: 53-66

83 Freilich L E, Reich P B. Will environmental changes reinforce the impact of global warming on the rairie-forest border of central North America? Front Ecol Environ, 2009, 8: 371-378

84 Volez S D, Williams J W, Blois J L, et al. No-analog climates and shifting realized niches during the late quaternary: Implications for 21st century predictions by species distribution models. Glob Chan Biol, 2012, 18: 1698-1713
85 Holdridge L R. Life Zone Ecology. San Jose: Tropical Science Center, 1967

86 Yin Y, Liu H, Hao Q, et al. Vegetation responses to mid-Holocene extreme drought events and subsequent long-term drought on the southeastern Inner Mongolia Plateau, China. Agr Forest Meteorol, 2013, 178-179: 3-9

87 Seneviratne S I, Corti T, Davin E L, et al. Investigating soil moistureclimate interactions in a changing climate: A review. Earth Sci Rev, 2010, 99: 125-161

88 Liu H, Cui H, Pott R, et al. Vegetation of the woodland-steppe ecotone in southeastern Inner Mongolia, China. J Veget Sci, 2000, 11: 525-532

89 Liu H, Yin Y, Zhu J, et al. How did forest respond to Holocene climate drying at the forest-steppe ecotone in northern China? Quat Int, 2010, 227: 46-52

90 Walter H. Ecology of Tropical and Subtropical Vegetation. Edinburgh: Oliver and Boyd, 1971

91 Scanlon T M, Albertson J D. Inferred controls on tree/grass composition in a savanna ecosystem: Combining 16-year normalized difference vegetation index data with a dynamic soil moisture model. Water Resour Res, 2003, 34: doi:10.1029/2002WR001881

92 Yin Y. Holocene vegetation evolution and its driving factors in the forest-steppe ecotone in the semi-arid region of China (in Chinese). Dissertation for the Doctoral Degree. Peking University, 2012

93 Cui H, Liu H, Dai J. Mountain Ecology and Alpine Timberline Research (in Chinese). Beijing: Science Press, 2005

94 D'Odorico P, He Y, Collins S, et al. Vegetation-microclimate feedbacks in woodland-grassland ecotones, Glob Ecol Biogeog, 2012, doi:10.1111/geb.12000

95 Holtmeier F-K. Mountain Timberline: Ecology Patchinees and Dynamics. Dordrecht-Boston-London: Kluwer Academic Publishers, 2003

96 Kirilenko A P, Belotelov N V, Bogaturev B G. Global model of vegetation migration: Incorporation of climatic variability. Ecol Model, 2000, 132: 125-133

97 Davis M B. Quaternary history and the stability of forest communities. In: West D C, Schugart H H, Botkin D B, eds. Forest Succession: Concepts and Application. New York: Springer, 1981. 132-153

98 Haxeltine A, Prentice I C. BIOME3: An equilibrium terrestrial biosphere model based on ecophysiological constraints, resource availability, and competition among plant functional types. Glob Biogeochem Cycle, 1996, 10: 693-709

99 Pearson R G, Dawson T P. Predicting the impacts of climate change on the distribution of species: Are bioclimate envelope models useful? Glob Ecol Biogeog, 2003, 12: 361-371

100 Fisher R, McDowell N, Purves D, et al. Assessing uncertainties in a second-generation dynamic vegetation model caused by ecological scale limitations. New Phytol, 2010, 187: 666-681

101 Dallmeyer A, Claussen M. The influence of land cover change in the Asian monsoon region on present-day and mid-Holocene climate. Biogeosciences, 2011, 8: 1499-1519

102 Lee X, Gu L, Katul G, et al. Observed increase in local cooling effect of deforestation at higher latitudes. Nature, 2011, 479: 384-387

Open Access This article is distributed under the terms of the Creative Commons Attribution License which permits any use, distribution, and reproduction in any medium, provided the original author(s) and source are credited. 